\title{
Em nome do público: jornalismo e política nas entrevistas dos
}

\section{presidenciáveis ao Jornal Nacional}

\section{Afonso de Albuquerque}

\section{Resumo}

Com base na análise da primeira rodada de entrevistas do Jornal Nacional, com os três candidatos mais bem colocados nas pesquisas durante a campanha eleitoral de 2010, o texto discute 0 modo como os entrevistadores reivindicam como representantes do interesse público, e o modo como ela se relaciona com a concepção liberal clássica do jornalismo como Fourth Estate.

\section{Palavra-Chave}

Entrevista. Jornal Nacional. Campanha eleitoral. Fourth Estate.
Afonso de Albuquerque I afonsoal@uol.com.br Doutor em Comunicação e Cultura pela Universidade Federal do Rio de Janeiro (UFRJ). Professor do Programa de Pós-Graduação da Universidade Federal Fluminense (UFF).

\section{Introdução}

Entre os dias 9 e 11 de agosto de 2010, o Jornal Nacional da Rede Globo de Televisão promoveu uma série de entrevistas com os três candidatos à Presidência da República mais bem colocados nas pesquisas de opinião pública. Seguindo uma ordem estabelecida por sorteio, Dilma Rousseff, do Partido dos Trabalhadores (PT), Marina da Silva, do Partido Verde (PV) e José Serra, do Partido da Social Democracia Brasileira (PSDB) foram sabatinados, por cerca de 12 minutos, pelos apresentadores do telejornal, William Bonner e Fátima Bernardes. Tais entrevistas podem ser analisadas de duas maneiras principais. A primeira tem em vista a campanha eleitoral, e investiga 0 impacto das entrevistas sobre a avaliação que o público faz dos candidatos e, em consequência, sobre as intenções de voto do eleitorado. Aqui, o foco da análise recai primariamente sobre os candidatos, considerados do ponto de vista das suas agendas políticas, suas estratégias retóricas, sua empatia, dentre outros aspectos. Os entrevistadores, por sua vez, desempenham um papel coadjuvante; sua 
atuação só se faz notar quando eles rompem com o comportamento imparcial que se espera deles. A segunda tem como foco o jornalismo, e considera as entrevistas com base em uma temporalidade mais ampla: 0 que elas revelam sobre os rumos do jornalismo brasileiro, particularmente aquele realizado pela Rede Globo de Televisão? É esta perspectiva que orienta o presente artigo.

Considerados sob este prisma, os candidatos desempenham um papel coadjuvante em relação aos seus entrevistadores. 0 que está em jogo é a autoridade que esses jornalistas reivindicam como representantes do interesse público, comumente descrita através de expressões como "cão de guarda" (watchdog) e Quarto Poder (Fourth Estate). Na prática, porém, tais concepções são vagas e revelam pouco sobre o modo como os jornalistas cumprem este papel. Concretamente, os jornalistas se valem de estratégias distintas para reivindicar sua autoridade como representantes do interesse público, ao longo da história e em diferentes culturas. As entrevistas dos presidenciáveis no Jornal Nacional abrem uma janela importante para entender como os jornalistas do telejornal de maior audiência do Brasil fazem isso nos dias de hoje. Trata-se, naturalmente, de um corpus bastante reduzido, mas isto obedece a uma estratégia metodológica definida. Por um lado, 0 foco em entrevistas realizadas em dias consecutivos e apresentadas como partes de um mesmo pacote contribui para maximizar a comparabilidade entre elas, uma vez que a padronização das circunstâncias em que elas ocorreram (a primeira entrevista feita com os candidatos no primeiro turno da campanha no Jornal Nacional) permite isolar mais facilmente as semelhanças e diferenças significativas no modo como os entrevistadores se dirigem aos candidatos. Por outro lado, este artigo se constitui antes como um esforço de elaboração de um modelo analítico, tendo em vista a proposição de uma agenda de pesquisa, do que de teste sistemático de uma hipótese.

0 artigo se estrutura em quatro partes. A primeira faz uma revisão crítica da bibliografia sobre a cobertura da política pelo jornalismo da Rede Globo desde 0 fim do regime militar, dando conta dos principais elementos de continuidade (e ruptura) que caracterizam essas análises. A segunda considera 0 modelo liberal, que serve de referente normativo para o jornalismo brasileiro, sob um prisma comparativo, tendo em vista a sua relação com os diferentes tipos de jornalismo partidário. A terceira parte do artigo analisa as questões feitas pelos entrevistadores aos três candidatos, tendo em vista semelhanças e diferenças significativas entre elas, enquanto a quarta parte discute o que estes resultados revelam sobre 0 tipo de autoridade que os entrevistadores do Jornal Nacional reivindicam exercer como legítimos representantes do interesse público.

\section{A política no Jornal Nacional: do Regime Militar à Era Lula}

Poucos temas, no âmbito da pesquisa brasileira sobre a comunicação política, têm recebido uma atenção tão duradoura e sistemática quanto 0 
tratamento que a Rede Globo - e particularmente o Jornal Nacional, o carro-chefe da sua programação jornalística - dispensa aos fenômenos políticos. Nascida em 1965 no Rio de Janeiro, a TV Globo soube se aproveitar das condições favoráveis oferecidas pelo regime militar brasileiro para se tornar a rede de televisão dominante no país - a tal ponto que se tornou comum referir a ela detentora de um monopólio de fato na televisão brasileira em troca do apoio político incondicional ao regime (ORTIZ, 1989). Os interesses das Organizações Globo e do regime militar permaneceram convergentes durante a maior parte do longo processo de transição democrática, como 0 demonstraram as coberturas das eleições diretas para governador do Rio de Janeiro em 1982 e na campanha pelas eleições diretas para presidente em 1984 (LIMA; RAMOS, 1988).

A relação simbiótica entre a Rede Globo e o regime militar foi de tal ordem que se poderia imaginar que 0 fim deste teria como consequência inevitável a decadência da emissora. Contudo, não foi isso o que ocorreu. Ao contrário, a redemocratização ofereceu à Rede Globo a oportunidade de evoluir, de um papel secundário para 0 de protagonista da vida política do país. No último momento, a emissora mudou de posição frente ao regime e, por ocasião das eleições indiretas para presidente, em 1985, passou a defender a candidatura do oposicionista Tancredo Neves, do Partido do Movimento Democrático Brasileiro (PMDB), contra o candidato do governista Partido Democrático Social (PDS), Paulo Maluf. Apoiado por dissidentes do regime - dentre os quais
José Sarney, ex-presidente do PDS que se tornou candidato a vice em sua chapa - Tancredo Neves terminou eleito pelo Colégio Eleitoral, encarregado de escolher o presidente. Contudo, acometido por uma grave doença, ele não chegou a tomar posse, vindo a falecer pouco depois. A enfermidade do presidente eleito, mas não empossado criou um impasse constitucional: quem deveria assumir? 0 vice-presidente eleito, José Sarney ou o presidente da Câmara de Deputados, Ulysses Guimarães? De acordo com Guimarães e Amaral (1988), a Rede Globo desempenhou um papel ativo na arbitragem da questão, mobilizando especialistas em apoio à tese de que José Sarney deveria ser empossado presidente, como de fato ocorreu.

Em 1989, as eleições diretas voltaram a ser realizadas no país. Dois candidatos com um perfil mais alternativo ao sistema - Luis Inácio Lula da Silva, do PT e Leonel Brizola, do Partido Democrático Trabalhista (PDT) - pareciam favoritos na disputa. Contudo, no início de 1989, eles foram ultrapassados nas pesquisas de opinião por Fernando Collor de Mello, membro de uma família tradicional da política alagoana, que se apresentou como um candidato antissistema, lançado pelo Partido da Reconstrução Nacional (PRN), um partido criado para dar sustentação à sua candidatura. No primeiro turno das eleições, o Jornal Nacional dispensou uma cobertura mais generosa para Collor do que para Lula e Brizola (LIMA, 2004); contudo, como observa Porto (2008, p. 265), ele recebeu menos tempo na televisão que Mário Covas, do PSDB e Ulysses Guimarães, do PMDB. ${ }^{1}$ 
A grande polêmica da cobertura da campanha pelo Jornal Nacional, porém, aconteceu no segundo turno da eleição, disputado por Collor e Lula. Na edição seguinte ao último debate entre os dois candidatos, e às vésperas da eleição, o Jornal Nacional apresentou uma edição amplamente favorável a Collor, sugerindo que ele havia "vencido" o debate contra Lula. 0 episódio provocou um forte mal estar mesmo entre os jornalistas da Rede Globo, ${ }^{2}$ a tal ponto que a emissora teria decidido não mais apresentar versões editadas de debates em futuras eleições (MEMÓRIA GLOBO, 2004).

As críticas à cobertura parcial do Jornal Nacional permaneceram a tônica dominante das análises desenvolvidas por estudiosos acerca das eleições de 1994 e 1998, ambas vencidas pelo candidato Fernando Henrique Cardoso, do PSDB. Contudo, o modus operandi da emissora teria sido muito diferente nos dois casos. Em 1994, verificou-se uma grande assimetria no tratamento dedicado ao candidato da situação, Fernando Henrique Cardoso, do PSDB em relação a Lula, seu principal adversário (ALBUQUERQUE, 1994), não apenas na quantidade de atenção dedicada a cada um, como no enquadramento adotado na sua cobertura: enquanto a campanha de Cardoso foi associada sistematicamente a valores consensuais e à capacidade de articular diferentes forças políticas em nome de um projeto, a campanha de Lula foi associada a causas polêmicas, ao conflito e a grupos de interesse particulares. Ainda mais importante, $o$ tratamento amplamente favorável dispensado pela Rede Globo ao Plano Real um plano de estabilização econômica lançado em fevereiro de 1994, e cuja "paternidade" foi atribuída a Cardoso, então ministro da Fazenda do presidente Itamar Franco - ajudou a garantir a Cardoso uma fácil vitória no primeiro turno das eleições (KUCINSKI, 1998; RUBIM; COLLING, 2004; PORT0, 2008).

Em 1998, o cenário da campanha eleitoral era totalmente diferente. Pela primeira vez um presidente democraticamente eleito se candidatava à reeleição, graças a uma reforma constitucional operada durante 0 mandato de Cardoso. Por outro lado, o governo enfrentava uma série de problemas econômicos. As análises disponíveis apontam dois traços importantes da cobertura que o Jornal Nacional dedicou à campanha e à política neste período. Por um lado, ele enfatizou a origem internacional da crise econômica e, deste modo, minimizou a responsabilidade do governo federal por ela, além de favorecer o argumento da campanha de Cardoso de que, diante de situações de crise, seria melhor contar com dirigentes experientes no comando do país. Por outro lado, o Jornal 
Nacional destinou uma atenção mínima à campanha e, deste modo, ajudou a minimizar as polêmicas relativas ao desempenho do governo Fernando Henrique Cardoso (MIGUEL, 2000).

0 tratamento dispensado pelo Jornal Nacional à campanha eleitoral de 2002 representou uma mudança significativa em relação às anteriores. Ao contrário do que havia acontecido em 1998, em 2002 a campanha presidencial teve grande destaque no telejornal, tendo ocupado cerca de $30 \%$ do tempo total da sua cobertura, contra os aproximadamente $8 \%$ destinados a ela na campanha anterior (MIGUEL, 2003; PORTO, 2008).

$\mathrm{E}$, diferentemente do que acontecera nas eleições de 1989 e 1994, o Jornal Nacional dispensou um tratamento notavelmente homogêneo aos candidatos no que diz respeito à quantidade de tempo na televisão e às sonoras destinadas aos candidatos, e também do ponto de vista qualitativo (MIGUEL, 2003; RUBIM; COLLING, 2004).

Ainda assim, o esforço do telejornal na direção da imparcialidade não deve ser superestimado: ele teria adotado, em sua cobertura, um enquadramento restrito, que enfatizava as "incertezas do mercado quanto ao resultado da eleição" - isto é, o medo das consequências de uma vitória da esquerda - antes que o governo Cardoso como o principal fator responsável pela instabilidade econômica pela qual passava o país; ao mesmo tempo, ele teria minimizado em sua cobertura os problemas sociais do país como tema de campanha (PORTO, 2007b). Além disso, o telejornal teria insistentemente cobrado dos candidatos o respeito aos compromissos já assumidos pelo atual governo, e a manutenção das linhas mestras da sua política econômica (MIGUEL, 2003). Desta vez, porém, Lula emergiu das urnas como o presidente eleito. Para além do seu significado histórico mais geral, a vitória de Lula nas eleições de 2002 tem uma importância especial para a discussão que travamos aqui: pela primeira vez a Rede Globo se viu diante da perspectiva de ter que lidar com um adversário histórico à frente do governo do país.

A cobertura da eleição presidencial de 2006 pelo Jornal Nacional recebeu uma atenção menor por parte dos pesquisadores. ${ }^{3}$ Sua importância, porém, não deve ser minimizada: pela primeira vez seria possível testar em que medida o tão comentado enfoque governista da Rede Globo no passado se deveria a um viés estrutural, intrínseco ao processo de produção de notícias - que, conforme destacado por inúmeros autores, tende a dar um tratamento privilegiado às autoridades governamentais como fontes privilegiadas de informação e, deste modo, reproduzir em boa medida os seus pontos de vista (CO0K, 1998; GANS, 1979; GITLIN, 1980; TUCHMAN, 1978) - ou a um alinhamento de caráter político/partidário. 0s dados apresentados por Souza (2007), tendo em vista quatro períodos da campanha - o período das pré-convenções, o período compreendido entre 0 
registro das candidaturas e 0 início da propaganda política na televisão, o período de campanha na televisão no primeiro turno, o segundo turno - oferece evidências significativas na segunda direção. Sistematicamente, Lula foi objeto de uma cobertura mais negativa do que seus adversários, principalmente na campanha para o primeiro turno, embora a cobertura tenha se tornado mais equilibrada na campanha para o segundo turno.

Não obstante existam evidências significativas de alinhamento político/partidário do Jornal Nacional, elas não esgotam todos os aspectos da sua cobertura das eleições. Para além de discutir a quem e contra quem a Rede Globo se posiciona politicamente, elas dizem pouco sobre o lugar específico que ela reivindica desempenhar no processo. Neste cenário, a pesquisa de Porto sobre as mudanças do telejornalismo da Rede Globo, a partir da metade da década de 1990, constitui uma exceção. 0 passo inicial do processo foi a substituição da dupla de apresentadores Cid Moreira e Sérgio Chapelin - o primeiro à frente do Jornal Nacional desde a sua primeira edição, em 1969 - por dois jornalistas, William Bonner e Lilian Witte-Fibe, que, além de apresentar 0 telejornal, assumiram funções editoriais nele. Segundo Porto, a mudança obedeceu a um investimento da emissora na credibilidade do seu telejornal, buscando romper com o estigma de "oficialista" que o caracterizava. 0s novos apresentadores não se limitavam a relatar as notícias, mas exerciam um papel interpretativo mais ativo em relação a elas (PORTO, 2002); ao mesmo tempo, a presença de autoridades governamentais nos telejornais diminuiu significativamente no período (PORT0, 2007a). Em um primeiro momento, as mudanças se traduziram em um movimento de tabloidização, com ênfase em matérias leves em detrimento da cobertura política, mas esta tendência teria sido revertida a partir de 2000, tal como demonstrado pela cobertura da campanha de 2002.

Porto argumenta que as mudanças promovidas pela Rede Globo no seu principal telejornal não podem ser explicadas como o resultado de uma tentativa de atender a demandas do público uma vez que os apresentadores originais gozavam de boa aceitação junto a ele nem como meramente um incremento na lógica comercial do jornalismo que explicaria, talvez, o primeiro movimento em direção a uma tabloidização, mas não 0 afastamento desta linha a partir de 2000. Ao invés disso, ele 0 descreve como uma tentativa de construir novas bases de legitimação, mais de acordo com os novos tempos democráticos. Mas que tipo de autoridade a Rede Globo reivindicou desempenhar nas campanhas eleitorais? A análise das entrevistas com os candidatos à presidente nas eleições de 2010 pode oferecer algumas pistas importantes a este respeito.

\section{0s jornalistas como agentes políticos}

Grosso modo, o tratamento dispensado ao Jornal Nacional é reproduzido pela maioria dos estudos brasileiros que relacionam o jornalismo 
à política. Neles, o jornalismo é frequentemente considerado do ponto de vista do seu produto - a cobertura jornalística - seus efeitos sobre a opinião pública e/ou seu alinhamento com esta ou aquela força política, mas dizem muito pouco sobre os jornalistas e as organizações jornalísticas como agentes sociais distintos, dotados de objetivos e métodos de atuação que lhes são próprios. Não obstante a atuação dos jornalistas e das organizações jornalísticas seja influenciada pelos seus interesses econômicos ou pela agenda de atores políticos aliados, ela não pode ser apropriadamente reduzida a eles. Os jornalistas e as organizações jornalísticas se dirigem aos agentes políticos e ao público em geral de um lugar que lhes é próprio.

Em particular, os jornalistas e organizações jornalísticas reivindicam desempenhar o papel de representantes dos legítimos interesses dos cidadãos. 0 modo como o fazem e os princípios a que recorrem para sustentar esta pretensão diferem amplamente, porém.

Os valores fundamentais que orientam 0 jornalismo e as práticas a eles associadas variam não apenas quando consideramos diferentes modelos de jornalismo, mas também no interior de um mesmo modelo. Isto fica claro quando consideramos o modelo de jornalismo "independente", dominante nos Estados Unidos, e que serve de referência para jornalistas e organizações jornalísticas de diversos países. Por detrás deste modelo, podemos identificar dois conjuntos de valores que são, em certa medida, autônomos entre si: 0 primeiro deles aponta para a tradição do jornalismo como um Fourth Estate, que identifica o jornalismo como um representante dos interesses dos cidadãos comuns frente às instituições do Estado; 0 segundo remete ao conceito de objetividade jornalística, que identifica no distanciamento emocional e político dos jornalistas em relação aos eventos que relatam um pré-requisito para a produção de informações confiáveis (ETTEMA; GLASSER, 1998). No primeiro caso, o jornalismo é associado explicitamente a um papel político, descrito como um agente essencialmente comprometido com a defesa da liberdade de expressão e um instrumento a serviço do aperfeiçoamento da cidadania, uma vez que cobra das autoridades governamentais uma prestação de contas dos seus atos. ${ }^{4}$ No segundo caso, o papel político também está presente, só que de modo implícito. De acordo com Cook (1998), é justamente na medida em que afirmam desempenhar um papel eminentemente técnico, e não político - isto é, "contar as coisas simplesmente como elas aconteceram", seguindo rotinas profissionais consagradas - que os jornalistas desempenham um papel político fundamental, como mediadores

Embora este tipo de discurso desempenhe um papel importante no esforço de auto-legitimação dos jornalistas e organizações jornalísticas, na prática o modelo de atuação a que ele se refere desempenha um papel bastante limitado no jornalismo, dadas as estritas amarras que unem as organizações jornalísticas às instituições-chave da vida econômica e política (SPARKS, 1995; SPARROW, 1999). 
do processo comunicativo entre as autoridades governamentais e o público e dentre as diferentes instituições que constituem o governo.

0 quadro se complica quando consideramos que o modelo de jornalismo independente a que nos referimos não é dominante em termos mundiais e, mesmo nos Estados Unidos, é um produto histórico relativamente recente: durante todo 0 século XIX e até a década de 1920 predominou neste país um tipo de jornalismo ferozmente partidário (KAPLAN, 2002; RYFE, 2006). De fato, Hallin (1994) situa o apogeu deste modelo entre as décadas de 1950 e 1980, e 0 associou ao fenômeno que denominou "consenso da guerra fria". Desde então, o modelo parece ter perdido parte do seu vigor. Nos demais países, o modelo de jornalismo independente jamais desempenhou um papel tão central. Na maior parte dos casos, é possível se referir ao jornalismo praticado nestes países como um tipo de "jornalismo partidário".

\section{0 termo "jornalismo partidário" tem sido} comumente utilizado de modo simplista, apresentado como um modelo homogêneo e oposto ao modelo de jornalismo "independente". Em muitos casos, os dois modelos são apresentados como etapas sucessivas de um processo evolutivo do jornalismo, seja ele definido nos termos da sucessão do modelo político pelo modelo comercial (GOLDENSTEIN, 1987; SILVA, 1990), ou pela expansão global do modelo americano de jornalismo (HALLIN; MANCINI, 2004). Usualmente, o emprego deste conceito estende para um âmbito global aspectos que só fazem pleno sentido em referência à experiência particular dos países da Europa Ocidental. Um exemplo disto é o conceito de "paralelismo político", comumente usado para ilustrar alguns aspectos importantes do modelo de jornalismo partidário. Os autores que se valem deste conceito (BLUMLER; GUREVITCH, 1995; HALLIN; MANCINI, 2004; SEYMOUR-URE, 1974) supõem como dadas algumas condições que não se apresentam em toda parte, como a existência de um sistema político partidário competitivo, e de partidos políticos consideravelmente institucionalizados, com identidades bem definidas e vínculos relativamente sólidos com o eleitorado. Ora, muito frequentemente o jornalismo de cunho partidário tem lugar em sistemas políticos não competitivos, como na União Soviética (ROUDAKOVA, 2009), na Polônia comunista (CURRY, 1990). Por outro lado, em sistemas partidários pouco estáveis, os veículos midiáticos dispõem de pouco incentivo para estabelecer laços profundos com os partidos e facções políticas, como McCargo (2003) sugere acerca da relação entre a mídia e a política na Tailândia.

Mais do que modelos reciprocamente excludentes, referentes a realidades empíricas distintas, o "jornalismo partidário" e o "jornalismo independente" devem ser entendidos como princípios normativos, alternativos em princípio, mas complementares na prática, através dos quais os jornalistas e as instituições jornalísticas buscam legitimar sua atuação pública. Do ponto de vista deste artigo, a questão não é se, em 
um dado país, os jornalistas e as organizações jornalísticas se filiam a um ou a outro modelo, mas de que modo ele aciona e articula os dois princípios no seu esforço de autolegitimação.

No caso do Brasil, o jornalismo teria se apropriado do discurso do Fourth Estate para legitimar um tipo de atuação política bastante distinto daquele encontrado no seu contexto original (isto é, 0 Reino Unido e os Estados Unidos). Implicitamente, ele faria apelo a uma noção totalmente diferente de quarto poder, fortemente enraizada na cultura política brasileira: o poder moderador. Criado pela Constituição imperial de 1824, ele deixou de existir formalmente com a proclamação da república, em 1891. Ainda assim, a percepção de que um sistema político baseado em três poderes independentes seria essencialmente frágil, e que a ação de uma quarta força seria necessária para que eles pudessem operar harmonicamente permaneceu influente (ALBUQUERQUE, 2005, 2010). Entre 1946 e 1964, as forças armadas desempenharam este papel. Após o fim do regime militar, o jornalismo teria clamado exercer a mesma função. 0 papel desempenhado pela Rede Globo no processo de legitimação de José Sarney como presidente do Brasil, a que nos referimos acima, fornece uma evidência disto. Em especial, o exercício deste papel se configuraria na figura do líder de opinião, responsável por esclarecer 0 público sobre a verdadeira natureza dos problemas enfrentados pelo país e os melhores caminhos a serem seguidos para resolvê-los. Na próxima parte tomaremos a primeira rodada de entrevistas dos candidatos à presidência no Jornal Nacional, na campanha eleitoral de 2010, como uma ocasião reveladora do tipo de autoridade que as organizações jornalísticas brasileiras, de um modo geral, e o Jornal Nacional em particular, reivindicam exercer.

\section{4 "0 Povo Merece Saber": entrevistas, jornalistas e representação}

As entrevistas jornalísticas se tornaram objeto de uma atenção considerável no âmbito da pesquisa internacional. Definidas por Schudson (1995) como "0 ato fundamental do jornalismo contemporâneo", as entrevistas têm sido consideradas sob diferentes ângulos pelos pesquisadores. Para começar os objetos de análise incluídos sob esta rubrica variam amplamente. A definição de Schudson se refere às entrevistas como um método de obtenção de informações que se aplica ao jornalismo de modo geral (embora o seu foco específico de análise recaia fundamentalmente sobre 0 jornalismo impresso). Clayman e Heritage (2002) discutem as entrevistas no contexto específico que elas assumem nas conferências de imprensa dos presidentes americanos. A grande maioria dos textos, contudo, tem nas entrevistas veiculadas pela televisão o seu objeto preferencial. Ainda assim, este grupo de textos está longe de ser uniforme. Ele inclui análises sobre entrevistas em profundidade, nas quais se verifica um diálogo intensivo entre entrevistador e entrevistado (CLAYMAN, 1988, 2002; CRAIG, 2010; FETZER, 
2006; MONTGOMERY, 2008), o uso de pequenos trechos de entrevistas em reportagens televisivas (EKSTRÖM, 2001; ERIKSSON, 2011; LUNDELL; ERIKSSON, 2010), e mesmo as interações entre jornalistas e políticos que têm lugar fora das câmeras, antes e depois da realização das entrevistas (LUNDELL, 2010).

0 foco destes estudos também varia consideravelmente. Alguns enfocam o discurso político, e o modo como ele é afetado pelas circunstâncias da entrevista (CRAIG, 2010; FETZER, 2006). Outros analisam as entrevistas de um ponto de vista formal, tendo em vista a sua classificação em diferentes tipos (LUNDELL; ERIKSSON, 2010; MONTGOMERY, 2008), ou as estratégias de descontextualização e recontextualização utilizadas pelos jornalistas no modo como se valem de trechos de entrevistas em suas matérias (EKSTRÖM, 2001). Finalmente, diversos textos identificam nas entrevistas um objeto privilegiado para discutir aspectos mais gerais do jornalismo: 0 modo como os jornalistas reivindicam uma posição de neutralidade nas entrevistas (CLAYMAN, 1988), buscam legitimar sua posição em situações de confronto com autoridades políticas (CLAYMAN, 2002), e se equilibram entre um modelo respeitoso ou adversário em relação a elas (CLAYMAN; HERITAGE, 2002; ERIKSSON, 2011).

Nossa análise das entrevistas do Jornal Nacional considera exclusivamente as questões formuladas pelos entrevistadores William Bonner e Fátima Bernardes, a dupla de âncoras do telejornal. Este método é semelhante ao empregado por Clayman e Heritage (2002), cuja análise comparativa da atuação dos jornalistas nas conferências de imprensa organizadas pelos presidentes Eisenhower e Reagan, também se concentrou no desenho das questões formuladas pelos jornalistas, antes que na interação entre entrevistadores e entrevistados. Isto não implica em desconhecer as diferenças fundamentais na situação dos candidatos, que interfere na lógica estruturadora das entrevistas. Dilma Rousseff, do PT, não apenas era a candidata da situação, como desempenhou um papel estratégico no governo Lula, como ministra chefe da Casa Civil. Por esta razão, a dimensão da accountability relativa ao governo atual se aplicava mais a ela que aos demais candidatos. Por outro lado, o papel de candidato da oposição parecia justificavelmente mais adequado a José Serra que a Marina da Silva. Não apenas Serra já havia disputado (e perdido) uma eleição contra Lula em 2002, como o PSDB, seu partido, protagonizara a disputa das últimas quatro eleições presidenciais do país (1994, 1998, 2002 e 2006) contra o PT (LIMONGI; CORTEZ, 2010); Marina da Silva, por outro lado, não apenas fora militante do PT até muito recentemente, como integrara o governo Lula, na qualidade de ministra do Meio Ambiente.

Quando consideramos as três entrevistas de uma perspectiva geral, percebemos um esforço dos entrevistadores no sentido de formatar as entrevistas dentro de um mesmo padrão (Quadro 1). Este esforço é explicitado no primeiro bloco das três entrevistas. Em todos os casos os entrevistadores destacaram a igualdade de condições oferecida 
aos três candidatos, expressa no tempo de 12 minutos concedido a eles, e à definição da ordem das entrevistas através de um sorteio, realizado na presença de representantes dos seus partidos. Além disso, as entrevistas dos candidatos se estruturaram em torno dos mesmos três temas, relativos: 1) à natureza das suas candidaturas e os problemas a elas associados; 2) ao problema das alianças políticas e o modo como os candidatos se situam em relação a elas; 3) ao desempenho do governo (ou da atuação do candidato no governo). Contudo, o modo como estas questões foram articuladas e o desenvolvimento que tiveram nas diferentes entrevistas variaram significativamente nas três entrevistas. Isto não é de se estranhar, considerandose que os candidatos apresentam trajetórias políticas diferentes, ocupavam posições distintas na disputa eleitoral, além da dinâmica particular de cada entrevista. Assim, para além das diferenças constatadas, podemos identificar um esforço de padronização no agendamento das questões dirigidas pelos entrevistadores aos três candidatos.

Quadro 1: Síntese das questões feitas aos candidatos pelos apresentadores do Jornal Nacional

\begin{tabular}{|c|c|c|}
\hline Entrevista Dilma Rousseff & Entrevista Marina Silva & Entrevista José Serra \\
\hline Apresentação, regras do jogo. & Apresentação, regras do jogo. & Apresentação, regras do jogo. \\
\hline Questões quanto à candidatura. & Questões quanto à candidatura. & Questões quanto à candidatura. \\
\hline Questões quanto às alianças políticas. & Questões quanto às alianças políticas. & Questões quanto às alianças políticas. \\
\hline $\begin{array}{l}\text { Questões quanto ao governo federal: } \\
\text { taxa de crescimento do país. }\end{array}$ & Ambiguidade em relação ao governo/PT. & Questões quanto à escolha do vice. \\
\hline $\begin{array}{l}\text { Questões quanto ao governo federal: } \\
\text { problema do saneamento básico. }\end{array}$ & $\begin{array}{l}\text { Atuação no governo federal: } \\
\text { gestão no Ministério do Meio Ambiente. }\end{array}$ & $\begin{array}{l}\text { Atuação no governo estadual de } \\
\text { São Paulo: problema do pedágio. }\end{array}$ \\
\hline Encerramento - Mensagem ao eleitor. & Encerramento - Mensagem ao eleitor. & Encerramento - Mensagem ao eleitor. \\
\hline
\end{tabular}

A similaridade no agendamento das questões oferece uma base comum, que permite verificar a existência de estratégias de enquadramento perceptíveis nas questões, ${ }^{5} \mathrm{e}$ se houve diferenças notáveis no tratamento dispensado aos candidatos. Comecemos com as questões levantadas pelos entrevistadores acerca das três candidaturas (Quadro 2). Em todos os casos os entrevistadores exploram aspectos potencialmente problemáticos, que

0 conceito de agendamento (agenda-setting) pela mídia se refere ao modo como ela seleciona os temas que se tornam objeto de discussão pública (McCOMBS;SHAW, 1972). Por sua vez, o conceito de enquadramento pela mídia (media framing) diz respeito ao ângulo sob o qual os assuntos que se tornam objeto da cobertura. Na definição clássica de Gitlin (1980, p. 7) "[0]s enquadramentos de media são padrões persistentes de cognição, de interpretação e de apresentação, de seleção, de ênfase e de exclusão, através dos quais os manipuladores-de-símbolos organizam habitualmente o discurso, seja ele visual ou verbal". 
indicariam possíveis fragilidades inerentes às diversas candidaturas, de modo a obrigar os entrevistados a se defenderem. Contudo, podemos identificar algumas diferenças no modo como eles foram tratados nas entrevistas dos três candidatos.

Quadro 2: Questões quanto às candidaturas

\begin{tabular}{|c|c|c|}
\hline Entrevista Dilma Rousseff & Entrevista Marina Silva & Entrevista José Serra \\
\hline $\begin{array}{c}\text { Indicação autoritária pelo presidente } \\
\text { Lula. }\end{array}$ & $\begin{array}{c}\text { Experiência especificamente voltada para } \\
\text { a questão do meio ambiente. }\end{array}$ & $\begin{array}{l}\text { Evita críticas ao presidente Lula. Não } \\
\text { assume o lugar de oposição. }\end{array}$ \\
\hline Falta de experiência eleitoral. & Apenas marcar posição. & Receio da popularidade de Lula. \\
\hline \multirow[t]{3}{*}{$\begin{array}{l}\text { Temperamento difícil - Maltrata outros } \\
\text { políticos. }\end{array}$} & & Compara biografias, mas não governos. \\
\hline & & $\begin{array}{l}\text { Demora na indicação do vice Índio da } \\
\text { Costa: perfil centralizador. }\end{array}$ \\
\hline & & $\begin{array}{l}\text { Inexperiência do candidato a vice - } \\
\text { carreira em âmbito municipal. }\end{array}$ \\
\hline
\end{tabular}

0 primeiro elemento que se destaca neste processo é a diferença do tratamento dispensado aos candidatos Dilma e Serra, de um lado, e a Marina, do outro.

Enquanto os dois primeiros têm demarcado 0 seu papel de competidores relevantes ao governo (Dilma do lado do governo e Serra, no da oposição), a candidatura de Marina é questionada no seu próprio propósito, uma vez que ela foi definida como monotemática - no que diz respeito à questão do meio ambiente - e questionada se sua intenção era apenas "marcar posição". Quanto a Dilma e Serra, à primeira vista, pode-se dizer que as suas entrevistas se estruturam com base em uma agenda comum: ambos são posicionados em relação a Lula e têm os seus temperamentos e/ou estilo pessoal, questionados.

As questões dirigidas a Dilma e a Serra questionam a sua passividade em relação ao presidente Lula. No caso de Dilma, a crítica se refere ao processo de sua escolha como candidata, passando por cima das bases do partido; quanto a Serra, ela destaca a sua hesitação em se assumir como candidato de oposição. Em ambos os casos, destaca-se, como subtexto, a presença autoritária e ameaçadora de Lula na campanha eleitoral. Além disto, merece destaque a ênfase com que os entrevistadores chamam a atenção de Serra para a necessidade de assumir mais ativamente o papel de candidato de oposição e comparar o governo atual e 0 anterior, em nome do interesse do eleitor.

No plano do temperamento/estilo pessoal, Dilma foi descrita como uma pessoa de "temperamento difícil" e Serra caracterizado como "centralizador", o que, em princípio, poderia 
ser descrito como um tratamento equivalente dispensado aos dois candidatos. Entretanto, aqui também podemos identificar diferenças significativas nos modos de tratamento dos dois candidatos. No caso de Serra, a caracterização de centralizador, feita pelos seus críticos é matizada pela observação de Fátima Bernardes de que "no seu discurso de despedida do governo de São Paulo, o senhor mesmo explicou sobre essa fama de centralizador". No caso de Dilma, a sua caracterização como portadora de um temperamento difícil é atribuída por Fátima Bernardes a "alguns críticos, muitos críticos e alguns até aliados". A eles, Bonner acrescenta o presidente, que "falou em maltratar". Diante da negativa da entrevistada, Bonner afirma que "o discurso dele está disponível". Desta forma, a versão da candidata é desqualificada por evidências empíricas apresentadas como absolutas. Em síntese, enquanto as perguntas dirigidas a Serra o colocam em uma posição de superioridade em relação à sua reputação uma vez que ele "a explica" - 0 questionamento a Dilma a coloca em posição de inferioridade - dado que sua interpretação é desmentida pela referência a evidências supostamente incontestáveis, visto que gravadas.

As alianças políticas também se tornaram alvo de questões dirigidas aos três candidatos. Aqui também, a análise comparativa revela interessantes padrões na atuação dos entrevistadores, sumarizados no Quadro 3. Mais uma vez, a questão se aplica diferentemente nas entrevistas de Dilma e Serra, de um lado, e na de Marina, do outro. Enquanto nos dois primeiros casos a existência de alianças heterogêneas é apontada como um problema, uma evidência de contradição política, na entrevista de Marina, a ausência de uma aliança política é que é posta em questão, tendo em vista os riscos potenciais que isto poderia implicar do ponto de vista da governabilidade, caso a candidata viesse a ser eleita. De um ângulo estritamente formal, 0 tratamento dado ao tema foi bastante similar nas entrevistas de Dilma e Serra: nos dois casos, a aliança firmada na campanha eleitoral é contrastada com as relações hostis que, no passado, o partido do candidato estabeleceu com as forças que agora 0 apoiam. Uma vez posta a questão, 0 entrevistador pergunta provocativamente se 0 partido do candidato errou antes ou agora.

Mais uma vez, para além das semelhanças formais no tratamento da questão das alianças nas entrevistas de Dilma e Serra encontramos algumas diferenças importantes. Por um lado, a questão dirigida a Dilma enfoca a dimensão personalista das suas alianças - 0 entrevistador menciona os nomes de Sarney, Renan Calheiros e Jader Barbalho, mas não o PMDB, partido a que todos eles pertencem, oficialmente coligado ao PT na disputa, além do apoio de Fernando Collor de Mello - enquanto na questão dirigida a Serra, a polêmica gira em torno do apoio do PTB, um partido que se envolveu no escândalo do mensalão em 2005. 0 único nome 
mencionado na questão (Maurício Marinho) pertence a uma figura sem carreira expressiva no partido. Em segundo lugar, na entrevista de Dilma as contradições de suas alianças políticas são apresentadas diretamente, sem rodeios; na entrevista de Serra, a contradição é inserida em um quadro mais amplo, e comparada à aliança do PT com "seus desafetos históricos". Finalmente, nas questões dirigidas a Serra 0 entrevistador promove uma associação direta entre o PT e a corrupção, enquanto o PSDB é retratado como um partido que a "investigou" e "condenou". 0 PT também foi alvo de questionamentos na entrevista com Marina da
Silva: ex-integrante do partido por muitos anos, ela foi seguidamente cobrada em relação ao seu comportamento passivo durante 0 episódio do mensalão, e instada a discorrer sobre o modo como viu a saída de alguns colegas do partido "indignados na época do mensalão, chorando". 0 comportamento do PT não foi objeto de nenhuma questão dirigida a Dilma, a candidata para quem a questão seria mais cabível sob a ótica da accountability.

0 último tópico das entrevistas se refere à atuação do governo - ou dos candidatos no governo considerada de uma perspectiva crítica. Contudo,

Quadro 3: Questões quanto às alianças políticas

\begin{tabular}{|c|c|c|}
\hline Entrevista Dilma Rousseff & Entrevista Marina Silva & Entrevista José Serra \\
\hline \multirow[t]{6}{*}{$\begin{array}{l}\text { Alianças com figuras que o PT rejeitava há } \\
\text { tempos atrás. Errou agora ou errou antes? }\end{array}$} & $\begin{array}{l}\text { Ausência de alianças com outros partidos. } \\
\text { Como formar uma base de governo? }\end{array}$ & $\begin{array}{l}\text { Contradições nas alianças políticas: } \\
\text { PT se aliou a desafetos; PSDB se aliou } \\
\text { ao PTB, que se envolveu no mensalão } \\
\text { petista. Errou agora ou errou antes, } \\
\text { quando criticou o PTB? }\end{array}$ \\
\hline & $\begin{array}{l}\text { Ausência de alianças aumenta o risco } \\
\text { de fisiologismo? }\end{array}$ & $\begin{array}{l}0 \text { PTB teve uma lista muito vasta (de } \\
\text { participantes no mensalão)... }\end{array}$ \\
\hline & PV tem quadros para governar o país? & $\begin{array}{l}\text { Não há constrangimento em estar ao } \\
\text { lado de um dirigente do PTB cassado } \\
\text { inclusive com votos do PSDB? }\end{array}$ \\
\hline & $\begin{array}{l}\text { Saiu por discordância do PT na questão } \\
\text { ambiental, mas não condenou o mensalão. } \\
\text { Conivência com os desmandos? }\end{array}$ & \\
\hline & $\begin{array}{l}\text { Desconforto não foi o bastante para } \\
\text { deixar o cargo de ministra? }\end{array}$ & \\
\hline & $\begin{array}{c}\text { Como viu a saída dos colegas que } \\
\text { deixaram o partido na ocasião, indignados? }\end{array}$ & \\
\hline
\end{tabular}


o enquadramento dado ao tema também variou amplamente nas entrevistas dos três candidatos (Quadro 4). 0 tema é mais explorado na entrevista de Dilma que na dos demais candidatos - a ela são feitas duas questões, enquanto os demais candidatos respondem a uma, apenas - o que faz sentido quando se considera que ela é a candidata oficial do governo federal. Não se pode descartar aqui, também, o fato de as entrevistas terem dinâmicas distintas, e que 0 impacto disto afeta principalmente 0 último bloco de questões. Ainda mais importante, as questões feitas aos três candidatos seguem lógicas distintas. Dilma é questionada sobre a performance do atual governo, mas não sobre a sua participação no governo. Nas duas questões feitas a ela - sobre o crescimento econômico do país e as políticas de saneamento básico - 0 discurso otimista do governo é contrastado com dados que sugerem resultados muito mais modestos. A crítica assume, aqui, o caráter de constatação de um fato objetivo, não sujeito a contestações. Marina, por sua vez, é questionada sobre seu desempenho como ministra do Meio Ambiente. Em especial, a entrevistadora aponta para a existência de muitas críticas "de gente do governo e fora dele" no que diz respeito ao atraso na liberação de licenças ambientais, o que acarretaria no risco de produzir "gargalos" na produção econômica. Serra, por fim, é questionado sobre a sua passagem pelo governo de São Paulo, controlado pelo seu partido há 16 anos e, em especial, sobre o sistema de pedágio do estado. Ainda que um elemento de crítica também esteja presente, ele assume uma forma diferente da que se verifica nas entrevistas dos outros candidatos. Para começar, a questão é precedida de um preâmbulo, no qual Serra é caracterizado como o sujeito de uma crítica ao modelo federal de concessão de estradas. Em seguida, o entrevistador afirma que muitos usuários se queixam do preço e da quantidade de pedágios das estradas paulistas e pergunta se 0 candidato pretende exportar para 0 âmbito do governo federal, o modelo estadual paulista. Após a resposta de Serra, enaltecendo a qualidade das estradas de São Paulo, em oposição às estradas federais, 0 entrevistador volta à carga perguntando se não existe um meio termo entre uma estrada boa e cara e outra barata e ruim. Desta forma, o entrevistador introduz um enunciado positivo associado ao modelo de Serra, que equilibra 0 enunciado negativo: as estradas são caras para 0 consumidor, mas são boas; enquanto as do governo federal são baratas, mas ruins. Desta forma, o que a princípio seria uma crítica, se transforma em uma comparação entre duas alternativas e uma pergunta sobre qual delas o candidato pretende seguir, caso seja eleito.

\section{Discussão}

0 que a análise comparativa dessas três entrevistas revela sobre o modo de atuação dos entrevistadores do Jornal Nacional e o tipo de autoridade que eles reivindicam exercer como mediadores das relações entre os cidadãos comuns/eleitores e os candidatos? Com relação ao primeiro aspecto, as entrevistas feitas com os três candidatos emitem 
Quadro 4: Questões quanto ao desempenho do/no governo

\begin{tabular}{|c|c|c|c|}
\hline & $\begin{array}{c}\text { Entrevista } \\
\text { Dilma Rousseff }\end{array}$ & $\begin{array}{c}\text { Entrevista } \\
\text { Marina Silva }\end{array}$ & $\begin{array}{c}\text { Entrevista } \\
\text { José Serra }\end{array}$ \\
\hline Objeto da questão & $\begin{array}{c}\text { Performance do } \\
\text { governo federal. }\end{array}$ & $\begin{array}{c}\text { Performance do } \\
\text { governo federal. }\end{array}$ & Políticas do governo estadual. \\
\hline $\begin{array}{c}\text { Tom do } \\
\text { questionamento }\end{array}$ & $\begin{array}{c}\text { Críticas "objetivas" } \\
\text { (fatos). }\end{array}$ & $\begin{array}{c}\text { Críticas "subjetivas" } \\
\text { (opiniões). }\end{array}$ & $\begin{array}{c}\text { Críticas "subjetivas"/ } \\
\text { comparação. }\end{array}$ \\
\hline $\begin{array}{c}\text { Estatuto do } \\
\text { candidato na questão }\end{array}$ & $\begin{array}{c}\text { Ausente } \\
\text { (foco no governo). }\end{array}$ & Objeto de críticas. & $\begin{array}{c}\text { Sujeito de críticas/ } \\
\text { objeto de críticas. }\end{array}$ \\
\hline
\end{tabular}

sinais contraditórios, em alguns casos relacionados a um tipo de jornalismo que se poderia identificar como "partidário" e, em outros, a um modelo de jornalismo "independente".

Por um lado, chama a atenção o esforço dos entrevistadores em se apresentar como ocupando um lugar transcendente em relação à disputa eleitoral. Este esforço se materializa através: 1) da insistência nas regras do jogo, idênticas para os três candidatos; 2) de um roteiro semelhante (ao menos do ponto de vista formal) de perguntas dirigidas a eles; 3) de uma atitude de questionamento agressivo adotada no tratamento de todos os candidatos (embora não necessariamente no mesmo grau); e, não menos importante, 4) do apelo ao interesse público como fundamento deste tipo de atitude. Tais elementos apontam na direção do uso de uma retórica baseada nos princípios do jornalismo independente e, mais especificamente, do Fourth Estate, para justificar a atuação dos entrevistadores.
Por outro lado, e em contradição com essa demanda de neutralidade, a análise do conjunto das entrevistas evidencia um tratamento mais favorável a Serra que aos demais candidatos: Marina foi apresentada como uma candidata não competitiva e ambígua na sua relação com 0 governo e o PT; as perguntas dirigidas a Dilma destacaram o seu temperamento "dificil" e minimizam a sua participação no governo federal, enquanto Serra foi instado a assumir mais claramente 0 seu papel como oposicionista e a comparar com o governo Lula o desempenho dos governos de seu partido, nos níveis federal e estadual. Além disso, alguns enquadramentos desfavoráveis a Dilma atravessaram mais de uma entrevista, como a ênfase na presença ameaçadora de Lula na campanha (nas entrevistas de Dilma e Serra) e a identificação do PT como partido fundamentalmente corrupto (nas entrevistas de Serra e Marina).

Quanto ao tipo de autoridade que os entrevistadores do Jornal Nacional exercem nas 
entrevistas com os candidatos à presidência, dois aspectos podem ser destacados. 0 primeiro aponta para o papel quase oficial, de instância de governo, que a Rede Globo clama desempenhar durante os processos eleitorais. Tendo por referência 0 caso americano, Cook (1998) também descreve as organizações jornalísticas como desempenhando uma função de governo, na medida em que cumpre funções essenciais na comunicação não apenas entre governo e cidadãos, mas também entre os três poderes do governo. Contudo, ele destaca que este papel somente pode ser exercido na medida em que os jornalistas reivindicam não exercer um papel político, e que este papel se projeta de maneira transorganizacional sobre 0 jornalismo como um todo (SOLOSKI, 1993). Em contraste, nas entrevistas o jornalismo da Rede Globo reivindica para $\mathrm{si}$ - antes que para 0 jornalismo de um modo geral - 0 exercício de uma função pública, e 0 faz de modo politicamente ativo. Neste sentido, a reivindicação de Bonner - feita na entrevista com Marina - de que atuava "em nome do público" parece fazer apelo a uma noção de mandato representativo.

0 segundo aspecto diz respeito ao comportamento autoritário dos entrevistadores do Jornal Nacional. É preciso distinguir este tipo de comportamento de uma postura agressiva ou adversária dos jornalistas em relação aos seus entrevistados. Em termos gerais, a postura adversária pode ser tomada como uma consequência direta do princípio do Fourth Estate, que pressupõe que os jornalistas devem cultivar uma relação distanciada em relação às autoridades de modo a que possam exercer a contento seu papel de informar os cidadãos sobre as questões publicamente relevantes. Por outro lado, a agressividade tem sido um traço intimamente associado às entrevistas desde a sua origem, de modo que no século XIX a entrevista era frequentemente criticada pelos europeus como uma prática americana "bárbara", na medida em que, nela, os jornalistas não demonstravam 0 devido respeito pelas autoridades políticas (SCHUDSON, 1995). Além disso, diversos estudos têm dado conta de um aumento da agressividade e de uma postura adversária dos jornalistas em relação às autoridades políticas nas democracias ocidentais desenvolvidas (EKSTRÖM, 2001; ERIKSSON, 2011; HALLIN, 1994). Em particular, Clayman e Heritage (2002) sugerem que esta tendência parece apontar tanto para um declínio da aura que cerca a instituição da presidência nos Estados Unidos, quanto para o esforço dos jornalistas no sentido de se legitimarem como agentes sociais responsáveis por promover a accountability das autoridades políticas frente ao público. Deste ponto de vista, a atuação dos entrevistadores do Jornal Nacional não estaria em desacordo com uma tendência mais ampla de agressividade dos jornalistas em relação aos seus entrevistados.

A história não acaba aí, porém. A bibliografia relativa aos Estados Unidos e países da Europa Ocidental destaca o esforço dos entrevistadores 
em cultivar uma atitude discreta, ao mesmo tempo em que questionam as autoridades políticas sobre temas controversos, tendo em vista 0 objetivo de "introduzir pontos de vista que contradizem os dos seus entrevistados, não para exprimir suas posições pessoais, mas como um meio para tornar mais claras as perspectivas dos entrevistados" (CLAYMAN, 1988, p. 490). Em contraste, os entrevistadores do Jornal Nacional desempenharam seu papel de modo muito mais ativo que seus colegas americanos. Mais do que questionar, eles se investem do poder de confrontar de modo explícito os candidatos, como no caso da pergunta "errou antes ou está errando agora?", feita aos candidatos Dilma e Serra. Por detrás dela, podemos identificar um juízo de valor tomado como um dado, expresso na ideia de que, em algum momento, um erro efetivamente ocorreu. Outros exemplos são as afirmações de que houve "desmandos", decorrentes de "um desvio moral de alguns integrantes do PT", feita durante a entrevista com Marina, e de que "há contradições muito claras" nas alianças formadas pelo PT e pelo PSDB, feita na entrevista com Serra. Em todos estes casos os entrevistadores do Jornal Nacional atuam como se sua autoridade interpretativa fosse autoevidente, expressão direta de uma verdade que se apresenta aos espectadores como absoluta. Chama a atenção, também, o esforço dos entrevistadores de conduzir as respostas dos entrevistados para um rumo "correto". $\mathrm{Na}$ entrevista com Marina, por exemplo, entre questões integralmente formuladas e tentativas de interromper sua argumentação - por meio de frases incompletas como "Só uma coisa, candidata..." - Bonner intervém dez vezes seguidas, na tentativa de extrair dela uma explicação sobre 0 fato de não ter abandonado 0 PT por ocasião do escândalo do mensalão.

Em conjunto, estas evidências sugerem que a atuação dos entrevistadores do Jornal Nacional se afasta do modelo liberal do Fourth Estate em dois aspectos importantes. Enquanto neste modelo, o papel do entrevistador se define como sendo o de apresentar questões que estimulem os entrevistados a expor, abertamente, os seus pontos de vista, de modo a ajudar os espectadores a formarem sua opinião sobre os temas em questão, os entrevistadores do Jornal Nacional demonstram um grande esforço no sentido de controlar as entrevistas, reduzindo a autonomia que os entrevistados têm para exporem suas respostas e, deste modo, conduzindo os espectadores a considerarem 0 assunto sob a sua dimensão "correta". Por outro lado, o exercício desta autoridade parece muito menos sujeito a limitações do que nas entrevistas americanas. Longe de se apresentarem como meros intermediários "neutros" e "objetivos" entre cidadãos e autoridades políticas, os entrevistadores do Jornal Nacional reivindicam para si um status político (mas não partidário): 0 de representantes por excelência do interesse popular. Tomadas em seu conjunto, eles 
apontam na direção da reivindicação -

fundamentalmente autoritária - do exercício do papel de "líder de opinião" pelos entrevistadores do Jornal Nacional.

\section{Referências}

ALBUQUERQUE, Afonso de. A campanha presidencial no 'Jornal Nacional'. Observações Preliminares.

Comunicação \& Política, Rio de Janeiro, v. 1, n. 1, p. 23-40, ago./nov. 1994.

. Another "Fourth Branch". Press and political culture in Brazil. Journalism, Londres, v. 6, n. 4, p. 486-504, maio, 2005.

. As três faces do Quarto Poder. In: BIROLLI, Flavia; MIGUEL, Luis Felipe. (Org.). Mídia, representação e democracia. São Paulo: Hucitec, 2010. p. 92-104.

ALDÉ, Alessandra; MENDES, Gabriel; FIGUEIRED0, Marcus (2007). Tomando partido: Imprensa e eleições presidenciais em 2006. In: ENCONTRO ANUAL DA COMPÓS, 16., 2007. Curitiba. Anais... Curitiba: Compós, 2007.

BLUMLER, Jay G.; GUREVITCH, Michael. The Crisis of Public Communication. London: Routledge, 1995.

CLAYMAN, Steven E. Displaying Neutrality in

Television News Interviews. Social Problems, v. 35, n. 4, p. 474-492, 1988.

CLAYMAN, Steven E. Tribune of the People: maintaining the legitimacy of agressive journalism. Media, Culture \& Society, Londres, v. 24, n. 2, p. 197-216, mar. 2002.

CLAYMAN, Steven E.; HERITAGE, John.

Questioning Presidents: Journalistic Deference and Adversarialness in the Press Conferences of U.S. Presidents Eisenhower and Reagan. Journal of Communication, Malden (MA), v. 52, n. 4, p. 749775, dez. 2002.
CONTI, Mario Sergio. Notícias do Planalto. São Paulo: Companhia das Letras, 1999.

C00K, Timothy. Governing with the News: The News Media as a Political Institution. Chicago: University of Chicago Press, 1998.

CRAIG, Geoffrey. Dialogue and dissemination in news media interviews. Journalism, Londres, n. 11, v. 1, feb. 2010.

\section{CURRY, Jane Leftwich. Poland's Journalists:}

Professionalization and Politics. Cambridge: Cambridge University Press, 1990.

EKSTRÖM, Mats. Politicians interviewed on television news. Discourse \& Society, Londres, v. 12, n. 5, p. 563584, set. 2001.

ERIKSSON, Göran. Adversarial moments: A study of short-form interviews in the news. Journalism, Londres, v. 12, n. 1, p. 51-69, jan. 2011.

ETTEMA, James S.; GLASSER, Theodore L. Custodians of Conscience: Investigative Journalism and Public Virtue. New York: Columbia University Press, 1998.

FETZER, Anita. "Minister, we will see how the public judges you". Media references in political interviews. Journal of Pragmatics, Filadélfia, n. 38 v.2, p. 180195, fev. 2006.

GANS, Herbert J. Deciding what's news: a study of CBS Evening News, NBC Nightly News, Newsweek and Time. New York: Pantheon Books, 1979.

GITLIN, Todd. The Whole World is Watching: Mass Media in the Making \& Unmaking of the New Left. Berkeley: University of California Press, 1980.

GOLDENSTEIN, Gisela Taschner. Do jornalismo político à indústria cultural. São Paulo: Summus, 1987.

GUIMARÃES, César; AMARAL, Roberto. Brazilian

Television: A rapid conversion to the new order. In: FOX, Elisabeth (Ed). Media and Politics in Latin América: The Struggle for Democracy. Newsbury Park (CA): Sage, 1988. p. $125-137$. 
HALLIN, Daniel C. We Keep America on top of the World: Television Journalism and the Public Sphere. London: Routledge, 1994.

HALLIN, Daniel C.; MANCINI, Paolo. Comparing

Media Systems: Three Models of Media and Politics. Cambridge: Cambridge University Press, 2004.

KAPLAN, Richard L. Politics and the American

Press: The Rise of Objectivity 1865-1920. Cambridge: Cambridge University Press, 2002.

KUCINSKI, Bernardo. A síndrome da antena parabólica. São Paulo: Editora da Fundação Perseu Abramo, 1998.

LIMA, Venício A. de. Mídia: teoria e política. 2.ed. São Paulo: Editora Fundação Perseu Abramo, 2004.

LIMA, Venício A. A mídia nas eleições de 2006. São Paulo: Fundação Perseu Abramo, 2007.

LIMA, Venício Artur de; RAMOS, Murilo César. A televisão no Brasil: desinformação e democracia. In: FLEISCHER, David. Da Distensão à Abertura: as Eleições de 1982. Brasília: Editora da UnB, 1988. p. 215-233.

LIMONGI, Fernando; CORTEZ, Rafael. As eleições de 2010 e 0 quadro partidário. Novos Estudos - CEBRAP, São Paulo, n. 88, p. 21-37, dez. 2010.

LUNDELL, Asa Kroon. The before and after of a political interview on TV: Observations of off-camera interactions between journalists and politicians.

Journalism, Londres, v. 11, n. 2, p. 167-184, fev. 2010.

LUNDELL, Asa Kroon; ERIKSSON, Goran . Interviews as communicative resources in news and current affairs broadcasts. Journalism Studies, Londres, v. 11, n. 1, p. $20-35$, fev. 2010 .

McCARG0, Duncan. Media and Politics in Pacific

Asia. London: Routledge, 2003.

McCOMBS, Maxwell; SHAW Donald L. The agenda-setting function of mass media. Public Opinion Quarterly, Oxford, v. 36 n. 2, p. 176-187, Summer, 1972.
MEMÓRIA GLOB0. (Org.). Jornal Nacional: a notícia faz história. Rio de Janeiro: Jorge Zahar Editor, 2004.

MIGUEL, Luis Felipe. The Globo television network and the election of 1998. Latin American Perspectives, Londres, v. 27, n. 6, p. 65-84, nov. 2000.

MIGUEL, Luis Felipe. A eleição visível: a Rede Globo descobre a política em 2002. Dados: Revista de Ciências Sociais, Rio de Janeiro, v. 46, n. 2, p. 289-310, 2003.

MONTGOMERY, Martin. The discourse of the broadcast news interview: A typology. Journalism Studies, Londres, v. 9, n. 2, p. 260-277, abr. 2008.

ORTIZ, Renato. A moderna tradição brasileira. São Paulo: Brasiliense, 1989.

P0RT0, Mauro P. Novos apresentadores ou novo jornalismo? 0 Jornal Nacional antes e depois da saída de Cid Moreira. Comunicação \& Espaço Público, Brasília, v. 5, n. 1 e 2, p. 9-31, dez. 2002.

. TV news and political change in Brazil: The impact of democratization on TV Globo's journalism. Journalism, Londres, v. 8, n. 4, p. 363-384, ago. 2007a. Framing Controversies: Television and the 2002 Presidential Election in Brazil. Political Communication, Filadélfia, v. 24, n. 1, p. 19-36, 2007b.

Democratization and Election News Coverage in Brazil In: STROMBACK, Jesper; KAID, Lynda Lee. (Org.). The Handbook of Election Coverage around the World. New York: Routledge, 2008. p. 252-272.

RENNÓ, Lucio. Escândalos e votos: as eleições presidenciais brasileiras de 2006. Opinião Pública, v. 13, n. 2, p. 260-282, 2007.

ROUDAKOVA, Natalia. Journalism as "Prostitution": Understanding Russia's Reactions to Anna Politkovskaya's Murder. Political Communication, Filadélfia, v. 26, n. 4, p. 412-429, 2009.

RUBIM, Antonio Carlos Albino; COLLING, Leandro. Mídia e eleições presidenciais no Brasil pós-ditadura. 
Comunicação \& Política, Rio de Janeiro, v. 22, n. 3, p. 169-189, mês de publicação, 2004.

RYFE, David M. News, Culture and Public Life. A study of 19th-century American journalism. Journalism

Studies, Londres, v. 7, n. 1, p. 60-77, fev. 2006.

SCHUDSON, Michael. The Power of the News.

Cambridge: Harvard University Press, 1995.

SEYMOUR-URE, Colin. The Political Impact of Mass

Media. London: Constable, 1974.

SILVA, Carlos Eduardo Lins da. 0 adiantado da hora: a influência americana sobre o jornalismo brasileiro.

São Paulo: Summus, 1990.

SOUZA, Fiorentina das Neves. 0 papel do Jornal Nacional nas eleições presidenciais de 2006. In:

CONGRESSO DA ASSOCIAÇÃO BRASILEIRA DE PESQUISADORES EM COMUNICAÇÃO POLÍTICA, 2., 2007. Belo Horizonte, Anais... Belo Horizonte: Compolítica, 2007.

SOLOSKI, John. News reporting and professionalism: some constraints in reporting the news. Media, Culture and Society, Londres, n. 11, v 2, abr. 1989. SPARKS, Collin. The Media as a Power for Democracy. Javnost (The Public), Lubliana, v. 2, n. 1, p. 45-49, 1995.

SPARROW, Bartholomew H. Uncertain Guardians.

\section{The News Media as a Political Institution.}

Baltimore: The Johns Hopkins University Press, 1999.

TUCHMAN, Gaye. Making News: a Study in the Construction of Reality. New York: The Free Press, 1978. 
On behalf of the public: journalism and politics in Jornal Nacional interviews with presidential candidates

\section{Abstract}

Based on the analysis of the first round of interviews the National Journal, with the three best-placed candidates in the polls during the 2010 election campaign, the text discusses how the interviewers claim as representatives of the public interest, and how it relates with the classical liberal conception of journalism as Fourth Estate.

\section{Keywords}

Interview. Jornal Nacional. Electoral Campaign. Fourth Estate .
En el nombre del público: periodismo y la política en las entrevistas de los candidatos presidenciales para el Jornal Nacional

\section{Resumen}

Basado en el análisis de la primera ronda de entrevistas el Diario Nacional, con los tres candidatos mejor colocados en las encuestas durante la campaña electoral de 2010, el texto analiza cómo afirman los encuestadores como representantes del interés público, y cómo se relaciona con la concepción liberal clásica del periodismo como Fourth Estate.

\section{Palabras-Clave}

Entrevista. Jornal Nacional. Campaña Electoral. Fourth Estate. 


\section{Expediente}

A revista E-Compós é a publicação científica em formato eletrônico da Associação Nacional dos Programas de Pós-Graduação em Comunicação (Compós). Lançada em 2004, tem como principal finalidade difundir a produção acadêmica de pesquisadores da área de Comunicação, inseridos em instituições do Brasil e do exterior.

\section{E-COMPÓS I www.e-compos.org.br I E-ISSN 1808-2599}

Revista da Associação Nacional dos Programas

de Pós-Graduação em Comunicacão.

Brasília, v.16, n.2, maio/ago. 2013

A identificação das edições, a partir de 2008

passa a ser volume anual com três números.

\section{CONSELHO EDITORIAL}

Afonso Albuquerque, Universidade Federal Fluminense, Brasil Alberto Carlos Augusto Klein, Universidade Estadual de Londrina, Brasil Alex Fernando Teixeira Primo, Universidade Federal do Rio Grande do Sul, Brasil Ana Carolina Damboriarena Escosteguy, Pontifícia Universidade Católica do Rio Grande do Sul, Brasi

Ana Gruszynski, Universidade Federal do Rio Grande do Sul, Brasil Ana Silvia Lopes Davi Médola, Universidade Estadual Paulista, Brasil André Luiz Martins Lemos, Universidade Federal da Bahia, Brasil Ângela Freire Prysthon, Universidade Federal de Pernambuco, Brasil Antônio Fausto Neto, Universidade do Vale do Rio dos Sinos, Brasil Antonio Carlos Hohlfeldt, Pontifícia Universidade Católica do Rio Grande do Sul, Brasil Antonio Roberto Chiachiri Filho, Faculdade Cásper Líbero, Brasil Arlindo Ribeiro Machado, Universidade de São Paulo, Brasil Arthur Autran Franco de Sá Neto, Universidade Federal de São Carlos, Brasil Benjamim Picado, Universidade Federal Fluminense, Brasil

César Geraldo Guimarães, Universidade Federal de Minas Gerais, Brasil Cristiane Freitas Gutfreind, Pontifícia Universidade Católica do Rio Grande do Sul, Brasil Denilson Lopes, Universidade Federal do Rio de Janeiro, Brasi Denize Correa Araujo, Universidade Tuiuti do Paraná, Brasil Edilson Cazeloto, Universidade Paulista , Brasi Eduardo Peñuela Cañizal, Universidade Paulista, Brasil Eduardo Vicente, Universidade de São Paulo, Brasil Eneus Trindade, Universidade de São Paulo, Brasi Erick Felinto de Oliveira, Universidade do Estado do Rio de Janeiro, Brasi Florence Dravet, Universidade Católica de Brasilia, Brasil Francisco Eduardo Menezes Martins, Universidade Tuiuti do Paraná, Brasil Gelson Santana, Universidade Anhembi/Morumbi, Brasil Gilson Vieira Monteiro, Universidade Federal do Amazonas, Brasil Gislene da Silva, Universidade Federal de Santa Catarina, Brasil Guillermo Orozco Gómez, Universidad de Guadalajara

Gustavo Daudt Fischer, Universidade do Vale do Rio dos Sinos, Brasil Hector Ospina, Universidad de Manizales, Colômbia

Herom Vargas, Universidade Municipal de São Caetano do Sul, Brasi leda Tucherman, Universidade Federal do Rio de Janeiro, Brasil Inês Vitorino, Universidade Federal do Ceará, Brasil Janice Caiafa, Universidade Federal do Rio de Janeiro, Brasil Jay David Bolter, Georgia Institute of Technology Jeder Silveira Janotti Junior, Universidade Federal de Pernambuco, Brasil João Freire Filho, Universidade Federal do Rio de Janeiro, Brasil John DH Downing, University of Texas at Austin, Estados Unidos
José Afonso da Silva Junior, Universidade Federal de Pernambuco, Brasi José Carlos Rodrigues, Pontifícia Universidade Católica do Rio de Janeiro, Brasi José Luiz Aidar Prado, Pontifícia Universidade Católica de São Paulo, Brasil José Luiz Warren Jardim Gomes Braga, Universidade do Vale do Rio dos Sinos, Brasil Juremir Machado da Silva, Pontifícia Universidade Católica do Rio Grande do Sul, Brasil Laan Mendes Barros, Universidade Metodista de São Paulo, Brasil Lance Strate, Fordham University, USA, Estados Unidos Lorraine Leu, University of Bristol, Grã-Bretanha Lucia Leão, Pontifícia Universidade Católica de São Paulo, Brasil Luciana Panke, Universidade Federal do Paraná, Brasil Luiz Claudio Martino, Universidade de Brasília, Brasil Malena Segura Contrera, Universidade Paulista, Brasil Márcio de Vasconcellos Serelle, Pontifícia Universidade Católica de Minas Gerais, Brasil Maria Aparecida Baccega, Universidade de São Paulo e Escola Superior de Propaganda e Marketing, Brasil

Maria das Graças Pinto Coelho, Universidade Federal do Rio Grande do Norte, Brasil Maria Immacolata Vassallo de Lopes, Universidade de São Paulo, Brasil Maria Luiza Martins de Mendonça, Universidade Federal de Goiás, Brasi Mauro de Souza Ventura, Universidade Estadual Paulista, Brasil

Mauro Pereira Porto, Tulane University, Estados Unidos Nilda Aparecida Jacks, Universidade Federal do Rio Grande do Sul, Brasi Paulo Roberto Gibaldi Vaz, Universidade Federal do Rio de Janeiro, Brasi Potiguara Mendes Silveira Jr, Universidade Federal de Juiz de Fora, Brasi Renato Cordeiro Gomes, Pontifícia Universidade Católica do Rio de Janeiro, Brasil Robert K Logan, University of Toronto, Canadá

Ronaldo George Helal, Universidade do Estado do Rio de Janeiro, Brasil Rosana de Lima Soares, Universidade de São Paulo, Brasi Rose Melo Rocha, Escola Superior de Propaganda e Marketing, Brasil Rossana Reguillo, Instituto de Estudos Superiores do Ocidente, Mexico Rousiley Celi Moreira Maia, Universidade Federal de Minas Gerais, Brasi Sebastião Carlos de Morais Squirra, Universidade Metodista de São Paulo, Brasil Sebastião Guilherme Albano da Costa, Universidade Federal do Rio Grande do Norte, Brasil

Simone Maria Andrade Pereira de Sá, Universidade Federal Fluminense, Brasi Tiago Quiroga Fausto Neto, Universidade de Brasília, Brasil Suzete Venturelli, Universidade de Brasília, Brasil Valério Cruz Brittos, Universidade do Vale do Rio dos Sinos, Brasil Valerio Fuenzalida Fernández, Puc-Chile, Chile

Veneza Mayora Ronsini, Universidade Federal de Santa Maria, Brasi Vera Regina Veiga França, Universidade Federal de Minas Gerais, Brasil

\section{COMISSÃO EDITORIAL}

Adriana Braga I Pontifícia Universidade Católica do Rio de Janeiro, Brasi

Felipe Costa Trotta I Universidade Federal Fluminense, Brasi CONSULTORES AD HOC

Alexandre Barbalho, Universidade Estadual do Ceará, Brasil

Ana Carolina Escosteguy, Pontifícia Universidade Católica do Rio Grande do Sul, Brasi

Ana Gruszynski, Universidade Federal do Rio Grande do Sul, Brasi

Arthur Ituassu, Pontifícia Universidade Católica do Rio de Janeiro, Brasil

Claudia Lahni, Universidade Federal de Juiz de Fora, Brasil

Francisco Paulo Jamil Marques, Universidade Federal do Ceará, Brasil

Jiani Bonin, Universidade do Vale do Rio dos Sinos, Brasil

José Luiz Braga, Universidade do Vale do Rio dos Sinos, Brasil

Leonel Aguiar, Pontifícia Universidade Católica do Rio de Janeiro, Brasil

Luciana Panke, Universidade Federal do Paraná, Brasil

Marcelo Kischinhevsky, Universidade do Estado do Rio de Janeiro, Brasil

Raquel Paiva, Universidade Federal do Rio de Janeiro, Brasil

Sandra Rubia da Silva, Universidade Federal de Santa Maria, Brasil

EDIČ̃̃ DE TEXTO E RESUMOS I Susane Barros

SECRETÁRIA EXECUTIVA I Juliana Depiné

EDITORAÇ̃̃o ELETRÔNICA I Roka Estúdio

TRADUÇÃO I Sieni Campos
COMPós I www.compos.org.br

Associação Nacional dos Programas de Pós-Graduação em Comunicação

Presidente

Eduardo Morettin

Universidade de São Paulo, Brasil

eduardomorettin@usp.br

Vice-presidente

Inês Vitorino

Universidade Federal do Ceará, Brasil

ines@ufc.br

Secretária-Geral

Gislene da Silva

Universidade Federal de Santa Catarina, Brasil

gislenedasilva@gmail.com 